\title{
Levels of Hemoglobin, ESR, Iron \& TIBC in Rheumatoid Arthritis Patients Compared with Normal Individuals
}

\author{
Authors \\ Dr. Shweta Dwivedi ${ }^{1}$, Dr Shreesh Singh $^{2}$, Dr Geeta Jaiswal ${ }^{3}$ \\ ${ }^{1}$ Assistant Professor, Department of Biochemistry, M.L.N. Medical College, Allahabad \\ ${ }^{2}$ Professor, Department of Pharmacy, M.L.N. Medical College, Allahabad \\ ${ }^{3}$ Professor, Department of Biochemistry, M.L.N. Medical College, Allahabad \\ Corresponding Author \\ Dr Shweta Dwivedi \\ Assistant Professor, Department of Biochemistry, M.L.N. Medical College, Allahabad \\ Email: shwetamishra_30@rediffmail.com, Mobile no.9838777289
}

\begin{abstract}
Rheumatoid Arthritis is a chronic multisystem disease of unknown etiology. One of the most common extraarticular features of rheumatoid arthritis is anemia. Iron plays a potential role in oxidative stress mediated injuries and pathologies eg. Rheumatoid arthritis (RA). In the present study, we investigated Hb\%, Iron \& Total iron binding capacity in RA patients. This study has been carried out 200 subjects, of which 100 subjects were control. The study found a significant decreased $\mathrm{Hb} \%$ and significantly lower levels of serum iron \&TIBC in RA patients as compared to control. The result suggested that routine dietary supplementation with multivitamins and a trace element is appropriate in rheumatoid arthritis patients.

Keywords: Rheumatoid arthritis, Anemia, Iron, TIBC
\end{abstract}

\section{Introduction}

Rheumatoid arthritis (RA) is a progressive, relapsing and chronic inflammatory disease. Although it affects about $1 \%$ of the adult population, its etiopathogenesis has not been fully revealed yet ${ }^{(1)}$. Anemia is a frequent comorbidity in patients with RA ${ }^{(2)}$.

The main types of anemia occurred in RA are iron deficiency anemia and anemia of chronic disease ( Majhi and Srivastava, 2010) ${ }^{(3)}$. Iron deficiency anemia is usually microcytic hypochromic while anemia of chronic disease is normocytic normochromic (Hove et al., 2000) ${ }^{(4)}$. Iron is a vital mineral to the human being required for erythropoiesis, oxygen transport, DNA synthesis and electron transport (Goodnough, 2011) ${ }^{(5)}$.

A recent prospective trial involving over 2000 patients with RA found that anemia (World Health Organization [WHO] Classification: hemoglobin (Hb) $<12 \mathrm{~g} / \mathrm{dl}$ in women and $<13 \mathrm{~g} / \mathrm{dl}$ in men) was present in $31.5 \%$ of patients, while the lifetime prevalence of anemia was estimated to be $57 \%{ }^{(6)}$. In patients with RA, anemia develops as a result of long standing disease (anemia of chronic disease $[\mathrm{ACD}]$ ) although other conditions such as iron deficiency may also be contributing factors ${ }^{(7}$, 8). Although the pathogenesis of ACD is not fully understood, several mechanisms have been 
proposed, including abnormalities of iron absorption ${ }^{(9)}$ and release from macrophages ${ }^{(10)}$ as well as malfunction of the cytokine network ${ }^{(11-16)}$, all of which can result in inadequate erythropoiesis. There is conclusive evidence to show that the presence of anemia in patients with chronic illnesses such as CKD, cancer, and HIV is associated with a substantial negative impact on morbidity, mortality, and quality-of-life (QOL) outcomes $^{(17,18)}$. While a few studies have also found similar associations between anemia and poor outcomes in patients with RA ${ }^{(6,19) \text {, }}$

Iron plays an important role in oxygen delivery, electron transport for energy procurement, the production of RNA by ribonucleotide reductase and cell division. However, iron is insoluble at physiological $\mathrm{pH}$ and can be toxic to living cells and tissues through a generation of oxygen-based radicals (i.e. oxidants). As a result of its absolute dependence on the metal and the potential for the introduction of an oxidative stress, the body has developed several mechanisms that allow the body adequate iron for critical cell processes while avoiding toxicity associated with its employment ${ }^{(20)}$.

Iron plays a potential role in oxidative stress mediated injuries and pathologies eg. rheumatoid arthritis (RA). Four decades ago it was suggested that iron may have a crucial role in the progression of in inflammation in RA. Indeed, free radicals generated by iron can cause damage to lipids, proteins, carbohydrates and DNA. It is this belived to occur in rheumatoid joint ${ }^{(21)}$.

The objective of this study to estimate the levels of ESR, Hemoglobin, Iron \& Total iron binding capacity in patients with rheumatoid arthritis as compared to control.

\section{Material \& Methods}

This study was undertaken in the Department of Biochemistry, Moti Lal Nehru Medical College, Allahabad. The study was performed in 200 individuals of different age (20-70 years). In this study we take 100 normal individual and 100 rheumatoid arthritis patient.

For the biochemical parameter to be analyzed, blood samples were drawn from the anticubital vein avoiding venostasis. In all subjects a blood sample was collected after an overnight fast. Plain \& double oxalate vials were used for the estimation of ESR, $\mathrm{Hb}$, Iron and TIBC respectively. ESR, $\mathrm{Hb}$ percentage, Iron and TIBC were measured by Wintrobe Method ${ }^{(22)}$, Cyanide Method $^{(23)}$ and Ferrozine Method ${ }^{(24)}$.

\section{Statistical Analysis}

The data are expressed as mean \pm sd. Statistical comparisons were performed by student $t$ test.

\section{Result}

in this study the level of hemoglobin is significantly decreased $(\mathrm{p}<0.001)$ in rheumatoid arthritis as compared to control. ESR is significantly increased in study group as compared to control. The Iron levels were significantly decreased in study group as compared to control. Decreased levels of total iron binding capacity found in study group as compared to control.

\section{Observation Table:}

\begin{tabular}{|l|l|l|l|}
\hline S.N. & Particulars & Control & Rheumatoid Arthritis(RA) \\
\hline 1 & $\mathrm{ESR}(\mathrm{mm} / \mathrm{hg})$ & $11.04 \pm 1.81$ & $24.33 \pm 3.21(\mathrm{p}<0.001)$ \\
\hline 2 & $\mathrm{Hb}(\mathrm{gm} / \mathrm{dl})$ & $12.29 \pm 0.79$ & $10.02 \pm 1.86(\mathrm{p}<0.001)$ \\
\hline 3 & $\operatorname{Iron}(\mu / \mathrm{dl})$ & $118.37 \pm 20.79$ & $68.22 \pm 47.11(\mathrm{p}<0.001)$ \\
\hline 4 & $\mathrm{TIBC}(\mu / \mathrm{dl})$ & $329.29 \pm 36.01$ & $170.94 \pm 90.74(\mathrm{p}<0.001)$ \\
\hline
\end{tabular}




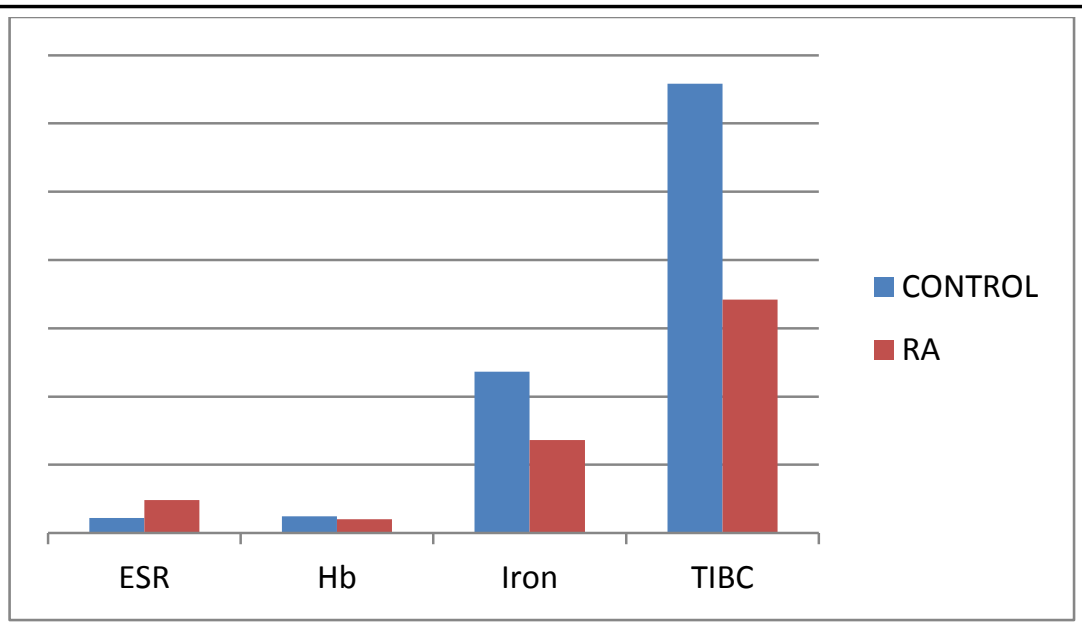

Figure: 1 Levels of ESR, $\mathrm{Hb}$, Iron and TIBC in RA patient compared to Control

\section{Discussion}

RA anemia is more likely to have more severe joint disease, and anemia correction may rates of disease response to treatment ${ }^{(25)}$. The causes of anemia in RA are not entirely clear although more than $60 \%$ of cases are anemia of chronic disease. Most common inflammatory rheumatic diseases are complicated by hematological abnormalities, including anemia, disorders of leukocytes, platelets, and the coagulation system, and hematological malignancy (26). Patients with rheumatoid arthritis (RA) may suffer from a variety of hematologic disorders, particularly anemia, leucopenia and thrombocytes.

In the present we found significantly decreased level of hemoglobin in study group as compared to control. Al Arfaj et al (27) also reported increased percent hemolysis and decreased $\mathrm{Hb}$ level in their study. Hemolysis can occur due to their oxidative effect on the lipids of RBC membranes.

Kamanli et al ${ }^{(28)}$ reported, significantly decreased hemoglobin levels in Rheumatoid arthritis patients as compared to control. This result is inconcordance with our findings.

According to Ravindra et al ${ }^{(29)}$ the hemoglobin, Iron and TIBC levels are significantly low in Rheumatoid arthritis patients as compared to healthy subject. These results are in concordance with our finding. Anemia of chronic disease frequently present in RA. Decreased iron absorption was shown to be the result of active
RA rather than a cause of ACD or iron deficiency. It has been hypothesized that bone marrow iron availability decrease due to decreased iron release by the mononuclear phagocyte system or that the anemia in ACD is due to ineffective erythropoiesis; these remain controversial theories (30)

Ayhan et al ${ }^{(31)}$ and his collageous reported low levels of hemoglobin in rheumatoid arthritis as compared to control. Nielson et al ${ }^{(32)}$ found a significant inverse correlation between the $\mathrm{Hb}$ concentration and ESR in the patients with rheumatoid arthritis.

Karatas et al ${ }^{(33)}$ and Thabrew et al ${ }^{(34)}$, found decreased mean hemoglobin concentration in rheumatoid arthritis patients as compared to control. Akyol et al (35) found no difference between $\mathrm{Hb}$ values of rheumatic patients and healthy individuals.

ESR showed an increase in patient group compared to the control group. Circulating human red blood cells posses the ability to scavenge ROS generated extracellularly by activated neutrophil. Hence, the RBC with decreased antioxidant levels is easily destroyed. The significantly decreased values of $\mathrm{RBC}$ and $\mathrm{Hb}$ in the blood of RA patients observed in our study are supported by other workers who reported that increased ROS production is inactive of $\mathrm{RBC}$ destruction in patients with RA. ${ }^{(36)}$

Agrawal et al ${ }^{(37)}$ and his collageous reported anemia in Rheumatoid arthritis patients as 
compared to control. In which they present low $\mathrm{Hb}$ levels, low serum iron levels and low serum ferritin levels in their study. Anemia is a frequent extra- articular manifestation in RA significantly Iron Deficiency Anemia (IDA) nearly half the patients. Partial response to iron replacement suggests a component of Anemia of Chronic diseases (ACD) had more active disease as compared with non-anemic patients or those with IDA.

Obtained results regarding the prevalence of anemia in RA were in accordance with those obtained by (Bear et al., 1987, Hochberg et al., 1988, Peeters et al.,1996, Tanaka et al., 1999, Wilson et al., 04 and van Santen et al., 2011) $)^{(38-43)}$ The degree of anemia in RA is related to disease activity and inflammation. Treatment of disease activity and erythropoietin therapy usually improve the anemia. The anemia of chronic disease (ACD) will not respond to iron. It is usually normochromic and normocytic (Porter et al., 1994 and Weiss et al.,2005) ${ }^{(44,45)}$.

\section{Conclusion}

On the basis of present findings we can concluded that arthritis patients have lower level of hemoglobin, higher levels of hemolysis and ESR as compared to control. Lower level of $\mathrm{Hb}$, Iron and increased levels of TIBC is a marker of IDA and ACD which plays a significant role in the etiopathogenesis in Anemia in Rheumatoid arthritis. An increased level of ESR and percent hemolysis is a marker of inflammation which plays a significant role in the etiopathogenesis of RA. Thus the assessment of blood hemoglobin may be helpful in prevention of anemia in the study group.

\section{Reference}

1. Fox DA. Etiology and pathogenesis of rheumatoid arthritis. In: Koopman WJ, Moreland LW,eds. Arthritis and allied conditions a text book of rheumatology. Fifteenth edition. Philadelphia; Lippincot Williams and Wilkins: 2005; 1089-1115.
2. Seth V, Kabra SK, Semwal OP, Jain Y. Clinico- immunological profile in juvenile rheumatoid arthritis- an Indian experience. Indian J Pediatr; 1996;63:293-300.

3. Majhi T. and Srivastava A.K. Iron deficiency in rheumatoid arthritis especially within the middle age. Int. J. Sys. Biol. 2010; 2 (1) : 1-5.

4. Hove L.V.; Schisano T. and Brace L. Anemia diagnosis, classification and monitoring using Cell-Dyn technology reviewed for the new Millenium. Lab. Hematol.2000; 6:93-109.

5. Goodnough, L.T. Iron deficiency syndromes and iron-restricted erythropoiesis. Transfusion.doi 10.1111/j. 2011537-2995.2011.03495.x

6. Wolfe f, Michaud k: Anemia and renal function in patients with rheumatoid arthritis. 56 b J Rheumatol 2006 ;33:1516-22.

7. Baer AN, Dessypris EN, Krantz SB: The pathogenesis of anemia in rheumatoid arthritis: a clinical and laboratory analysis. Semin Arthritis Rheum 1990; 19: 209-23.

8. Vreugdenhil G, Wognum aw, Van eijk hg et al.: Anaemia in rheumatoid arthritis: the role of iron, vitamin B12, and folic acid deficiency, and erythropoietin responsiveness. Ann Rheum Dis 1990; 49: 93-8.

9. Weber J, Werre JM, Julius HW et al.: Decreased iron absorption in patients with active rheumatoid arthritis, with and without iron deficiency. Ann Rheum Dis s 1988; 47: 404-9.

10. Bentley DP, Cavill I, Ricketts C et al.: A method for the investigation of reticuloendothelial iron kinetics in man. $\mathrm{Br}$ J Haematol1979; 43: 619-24.

11. Davis D, Charles PJ, Potter A et al.: Anaemia of chronic disease in rheumatoid arthritis: in vivo effects of tumour necrosis factor alpha blockade. $\mathrm{Br} \mathrm{J}$ Rheumatol 1997; 36: 950-6.

12. Mamus SW, Beck-Schroeder S, Zanjanied: Suppression of normal human 
erythropoiesis by gamma interferon in vitro. Role of monocytes and $T$ lymphocytes. J Clin Invest 1985; 75: 1496-503.

13. Means Rt, JR: Pathogenesis of the anemia of chronic disease: a cytokine-mediated anemia. Stem Cells 1995; 13:32-7.

14. Peeters HR, Jongen-Lavrencic M, Vreugdenhil $G$ et al.: Effect of recombinant human erythropoietin on anaemia and disease activity in patients with rheumatoid arthritis and anaemia of chronic disease: a randomised placebo controlled double blind 52 weeks clinical trial. Ann Rheum Dis 1996; 55: 739-44.

15. Nemeth E, Rivera S, Gabayan V et al.: IL6 mediates hypoferremia of inflammation by inducing the synthesis of the iron regulatory hormone hepcidin. J Clin Invest 2004; 113:1271-6.

16. Maury CP, Andersson lc, Teppo AM et al.: Mechanism of anaemia in rheumatoid arthritis: demonstration of raised interleukin1 beta concentrations in anaemic patients and of interleukin 1 mediated suppression of normal erythropoiesis and proliferation of human erythroleukaemia (HEL) cells in vitro.Ann Rheum Dis 19.

17. Martí-Carvajal AJ, Solà I: Treatment for anemia in people with AIDS. Cochrane Database Syst Rev 2007; CD004776.

18. Strippoli gf, Manno C, Schena FP et al.: Haemoglobin and haematocrit targets for the anaemia of chronic renal disease. Cochrane Database Syst Rev 2003; CD003967.

19. Doube A, Davis M, Smith JG et al.: Structured approach to the investigation of anaemia in patients with rheumatoid arthritis. Ann Rheum Dis 1992; 51: 46972.

20. Andrews NC, Schmidt PJ. Iron homeostasis. Annu Rev Physiol
2007;69:69-85. Cross Ref Medline Web of

Science Google Scholar

21. Sang- Cheol Bae, MD, PhD, MPH, SooJin Kim, MSc, Mi-Kyung Sung, PhD. (2003), Inadequate Antioxidant Nutrient Intake and Altered Plasma Antioxidant Status of Rheumatoid Arthritis Patients. Journal of the American College of Nutrition. 22, 4, 311-315.

22. Wintrobe's method. Medical Laboratory Technology. Ramnik Sood. Pg. 184-185.

23. Beutler E. Red Cell Metabolism: A manual of Biochemical methods, $3^{\text {rd }}$ ed. (Graune $\&$ Stratton Inc. New York) 68-71.

24. Fossati, P. Ann.Clin. Biochem. 1980, $6: 2$ 4.

25. Wilson A, Yu HT, Goodnough LT, Nissenson AR. Prevalence and outcomes of anemia a systematic review of the literature. Am J Med. 116 (suppl): 2004; 505- 575.

26. Hamilton, P J. The hematology laboratory and the rheumatologist. Clin Rheum Dis. 1983; 9:69.

27. Al Arfaj AS. Serum uric acid and radiographic osteoarthritis. J Pak Med Assoc. 2003; 53: 187-189.

28. Kamanli A. Naziroglu M, AydileKN, Hacievliyagil C. Plasma lipid peroxidation and antioxidant levels in patients with rheumatoid arthritis. Cell Biochem Funct. 2004: 22 (1): 53-7.

29. Vinod Ravindran, Sandeep jain and Dinesh S. Mathur. The differentiation of aneamia in rheumatoid arthritis: parameters of iron- deficiency in an Indian rheumatoid arthritis population; Rheumatology International.2007.

30. Dallaiio G, Means RT. Effect of oxidative stress on human erythroid colony formation: modulated by gammainterferon. The Journal of Laboratory and Clinical Medicine.2003; 141:395-400.

31. Ayhan Kamanll, Mustafa Nazlroglu, Nurettin Aydllek, Cengiz Haclevllyagill. 
Plasma lipid-peroxidation and antioxidant levels in patients with rheumatoid arthritis. Cell Biochemistry and function. 2003; 22, 1,53-57.

32. Nielson OJ , Anderson LS, Ludwigsen E, Bouchelouche P, Hansen TM, Birgens H, Hansen NE. (1990). Anemia of rheumatoid arthritis: Serum erythropoietin concentrations and red cell distribution width in relation to iron status. Ann Rheum Dis. 49 (6): 349-53.

33. F. Karatas, I. Ozates, H. Canatan, M. Karatepe and R. Colok. Antioxidant status and lipid-peroxidation in patients with rheumatoid arthritis. Indian J Med Res. 2003:118; 178-181.

34. Thabrew MI, Senaratna L, Samarawickrema N, Munasinghe C. (2001). Antioxidant potential of two polyherbal preprations used in Ayurveda for the treatment of rheumatoid arthritis. J Ethnopharmacol; 76: 285-91.

35. Akyol O, Isci N, Temel I, Ozgocmen S, UzE. (2001). The relationship between plasma and erythrocyte antioxidant enzymes and lipid peroxidation in patients with rheumatoid arthritis. Joint Bone Spine; 68: 311-7.

36. Hassan MQ, Hadi RA, AI- Rawi ZS, Padron VA, Stohs SJ. The glutathione defense system in the pathogenesis of rheumatoid arthritis. J Appl Toxicol.2001; 21(1): 69-73.

37. Agarwal Sumeet; Mishra Ramnath; Aggarwal Amia. Anemia in rheumatoid arthritis: high prevalence of irondeficiency anemia in Indian patients. Rheumatology International. 2006:26: 12; 1091-1095

38. Bear A. N.; Dessypris E. N.; Goldwasser E.; andKrantz S. B. Blunted erythropoietin response to anaemia in rheumatoid arthritis. Br. J.Haematol. 1987; 66: 55964.
39. Hochberg M.C.; Arnold C.M.; Hogans B.B.; Spivak J.L. Serum immunoreactive erythropoietin in rheumatoid arthritis: impaired response to anemia. Arthritis Rheum. 1988; 31(10):1318-21.

40. Peeters H.R.; Jongen-Lavrencic M.; Raja A.N. Course and characteristics of anemia in patients with rheumatoid arthritis of recent onset.Ann. Rheum. Dis.1996; 55:162-168.

41. Tanaka N.; Ito K.; Ishii S. and Yamazaki I.Autologous blood transfusion with recombinant erythropoietin treatment in anaemic patients with rheumatoid arthritis. Clin Rheumatol. 1999;18: 293-8.

42. Wilson A.; Yu H.T.; Goodnough L. and Nissenson A.R. Prevalence and outcomes of anemia in rheumatoid arthritis: a systematic review of the literature. Am J Med.; 116 Suppl. 7A. 2004:50S-57S.

43. Van Santen S.; van Dongen-Lases E. C.; de Vegt, F.; Laarakkers C. M. M.; van Riel P. L. C. M.;van Ede A. E. and Swinkels D. W. Hepcidin and hemoglobin content parameters in the diagnosis of iron deficiency in rheumatoid arthritis patients with anemia. Arthritis \&Rheumatism. 2011; 63: 3672-3680.

44. Porter D.R.; Sturrock R.D. and Capell H.A.Address Centre for Rheumatic Diseases, Glasgow Royal Infirmary, U.K. Source. Clin Exp Rheumatol, 1994:12(2): 179-82.

45. Weiss G. and Goodnough L.T. Anemia of chronic disease. N. Engl. J. Med.2005; 352(10):1011-23. 